\title{
PEAK GROUND MOTION CHARACTERISTICS
}

\author{
JoJI EJIRI ${ }^{i}$, Sumio SAWADA ${ }^{\text {ii), }}$ Yozo Goto ${ }^{\text {iii) }}$ and Kenzo ToKI ${ }^{\text {iv) }}$
}

\begin{abstract}
More than 200 strong ground motions were observed during the 17 January 1995 Hyogoken-Nambu earthquake over a wide variety of subsurface ground conditions including rock and stiff or soft soils. Key parameters of the records, such as peak ground acceleration values (PGAs), were immeadiately published by many organizations, such as CEORKA (the Committee of Earthquake Observation and Research in the Kansai Area), JMA (the Japan Meteorological Agency), PWRI (the Public Works Research Institute, Ministry of Construction), PHRI (the Port and Harbour Research Institute, Ministry of Transport), RTRI (Railway Technical Research Institute, Japan Railway Companies), the Kansai Electric Power Co., Osaka Gas Co. and others. This paper presents a preliminary overview of strong ground motion characteristics using these records especially focussing on peak ground acceleration. The main results of this study are that (1) $\mathrm{S}$ wave radiation from strike slip fault can explain the regional distribution of PHGAs during this event, (2) High PGAs observed in the strike direction area have been strongly affected by the directivity effect and (3) The unusually small PHGA/PVGA ratios near the fault rupture zone have resulted from the strong nonlinearlity of the subsurface soils.
\end{abstract}

Key words: attenuation characteristics, directivity effect, equivalent hypocentral distance, fault model, peak ground acceleration (PGA), regression analysis, stochastic synthesis method (IGC: E8)

\section{REGIONAL ASPECTS OF PEAK GROUND ACCELERATION}

Figure 1 presents the regional distribution of the peak horizontal ground acceleration values (PHGAs). These PHGAs are classified into five levels which approximately represent JMA intensity scale. It is clear from this figure that high PHGAs greater than 400 gal were observed near and around the fault rupture zone shown by Kikuchi (1995). These high PHGAs were recorded at Fukiai Gas Supply Depot (833 gal), Kobe Marine Meteorological Observatory (818 gal), CEORKA KobeMotoyama Station (774 gal), JR Takarazuka (694 gal), JR Takatori (666 gal), Shin-kobe Electric Substation (584 gal) and other 12 recording sites. It is interesting to note that high PHGAs greater than 250 gal occurred as far away as Kyoto, which is located in the fault strike direction area at a distance of $54 \mathrm{~km}$ from the fault rupture.

Figure 2 shows the regional distribution of the major principal axes which yield maximum values for the covariance (i.e. RMS) calculated using two horizontal components of the recorded accelerograms. Near and adjacent to the fault rupture zone, the major principal axes point generally in a direction perpendicular to the fault strike. In general, it has been well recognized that the orientation of major principal axes of strong ground motion are

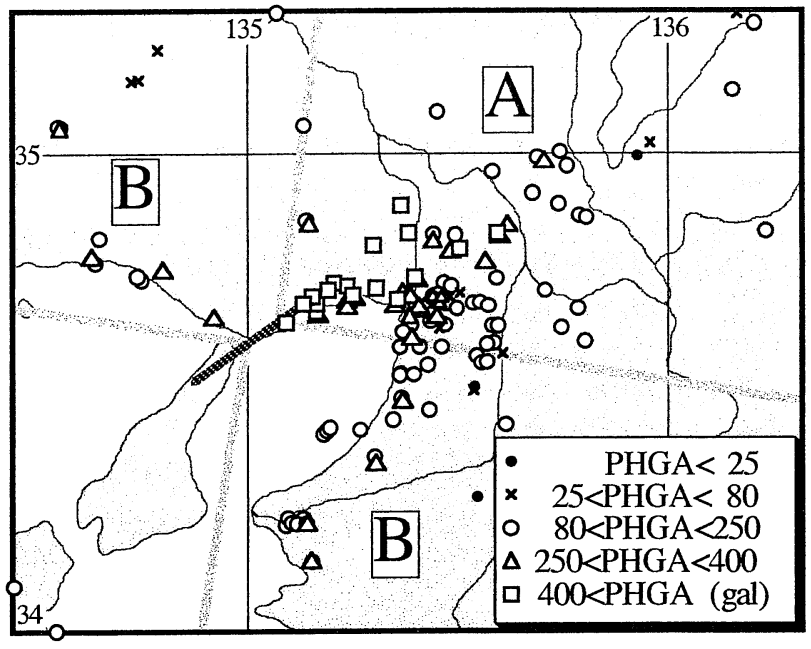

Fig. 1. Regional distribution of the PHGA records

i) Deputy Chief Research Engineer, Technical Research Institute of Obayashi Corporation, 4-640, Shimokiyoto Kiyose-shi, Tokyo 204.

ii) Instructor, School of Civil Engineering, Kyoto University, Yoshidahonmachi, Kyoto 606.

iii) General Manager, Technical Research Institute of Obayashi Corporation.

iv) Professor, School of Civil Engineering, Kyoto University. Manuscript was received for review on August 17, 1995.

Written discussions on this paper should be submitted before August 1, 1996, to the Japanese Geotechnical Society, Sugayama Bldg. 4F, Kanda Awaji-cho 2-23, Chiyoda-ku, Tokyo 101, Japan. Upon request the closing date may be extended one month. 


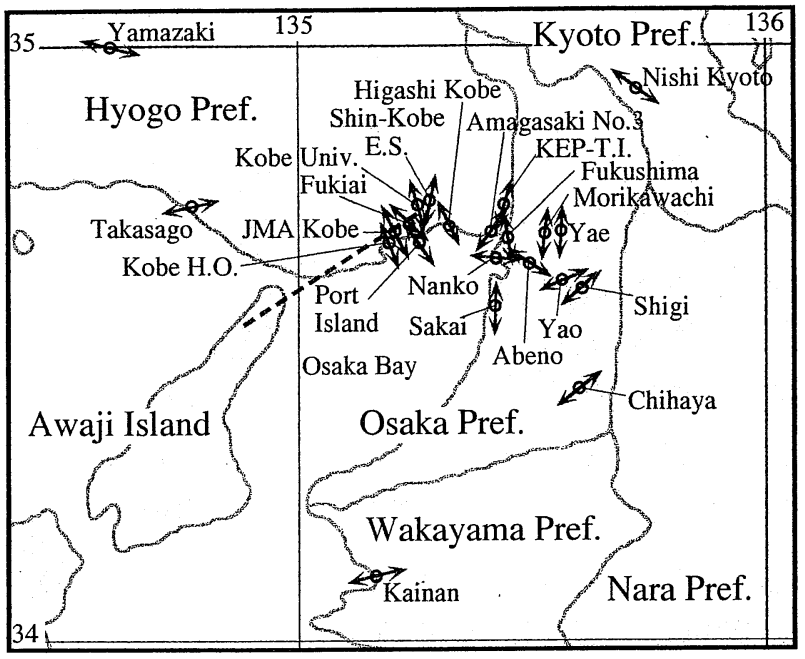

Fig. 2. Regional distribution of the major principal axes

strongly affected not only by fault mechanism but also local site effects depending on the geological and topographical conditions at each of the recording sites. During this event, however, this aspect related to the orientation of major principal axes seems to be independent of subsurface ground conditions near the fault rupture zone (n.b. Port Island, Kobe Harbour Office and Higashi Kobe bridge are located on deep alluvial deposits).

For this reason, it was assumed that the major ground motions during this event was strongly affected by the source mechanism. Therefore an attempt was made to explain the above mentioned aspects using the Stochastic Synthesis Method (SSM) proposed by Kamae et al. (1991), which can simulate the shear wave (SH) radiation caused by the rupture process of faulting including both radiation pattern and directivity effect. The source chanism solution proposed by Kikuchi (1995) was used, which was obtained through the inversion analysis by means of the IRIS (Incorporated Research Institutions for Seismology) dataset consisted of long-period motions. The source mechanism was assumed to be rightlateral strike slip and divided into three segments. The properties used in this analysis are shown in Fig. 3 and
Table 1. Figure 4 shows the regional distribution of magnitudes of simulated PHGAs on "bedrock outcroppings" having an assumed S wave velocity (Vs) of 3.6 $\mathrm{km} / \mathrm{sec}$. The component of $\mathrm{SH}$ wave amplitudes corresponds to the direction perpendicular to the fault strike. It can be seen in this figure that the simulated regional distribution of PHGAs has a similar tendency to that of the recorded one. It was concluded from this that the regional distribution of PHGAs during this event was strongly affected by the fault mechanism.

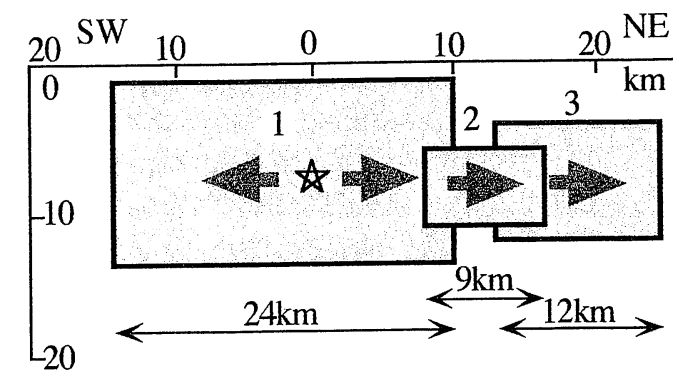

Fig. 3. Fault composed of three segments

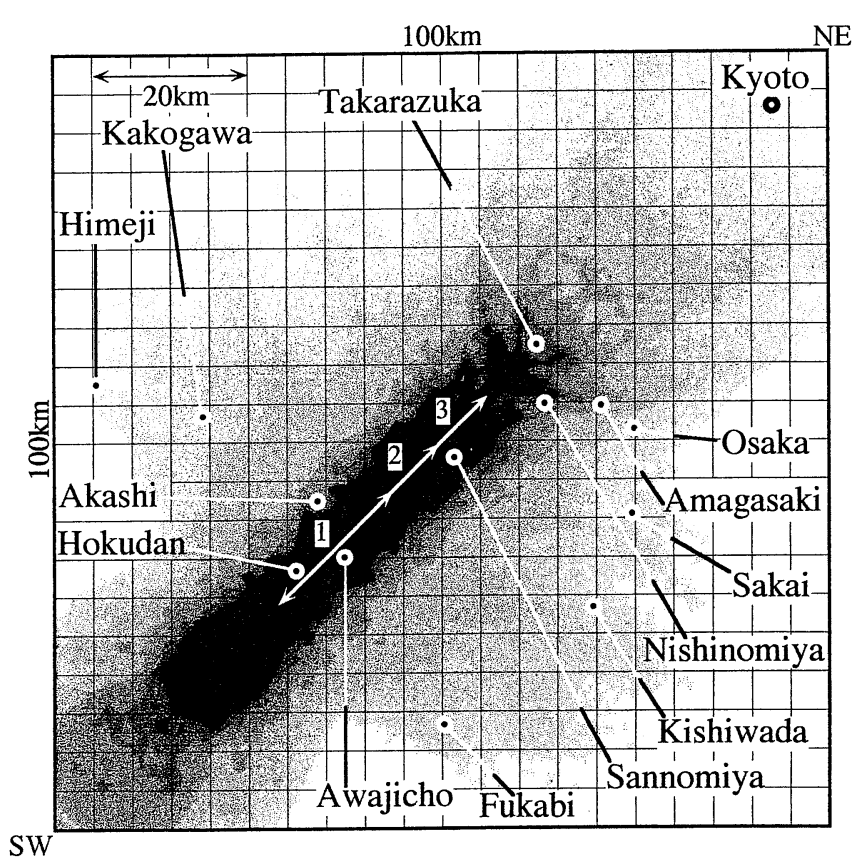

Fig. 4. Contour of magnitudes of the simulated PHGAs

Table 1. Source mechanism of three segments

\begin{tabular}{|c|c|c|c|c|c|}
\hline & $\begin{array}{c}\text { Mechanism } \\
\text { (strike, dip, rake) } \\
\text { degree }\end{array}$ & $\begin{array}{l}\text { Seismic moment } \\
\times 10^{19} \mathrm{Nm}\end{array}$ & $\begin{array}{l}\text { Duration } \\
\text { sec }\end{array}$ & $\underset{\mathrm{km}^{2}}{\text { Area }}$ & $\begin{array}{l}\text { Composed offset } \\
\text { (lateral, vertical) } \\
\text { m }\end{array}$ \\
\hline Segment 1 & $(231,87,172)$ & $1.89\left(M_{w} 6.8\right)$ & $0-6$ & $24 \times 12$ & $2.1(2.1,0.3)$ \\
\hline Segment 2 & $(207,54,88)$ & $0.21\left(M_{w} 6.1\right)$ & $4-9$ & $9 \times 5$ & $1.6(0.1,1.6)$ \\
\hline Segment 3 & $(238,88,155)$ & $1.56\left(M_{w} 6.4\right)$ & $6-11$ & $12 \times 6$ & $2.6(2.4,1.1)$ \\
\hline Mean & $(233,86,167)$ & & & & $2.1(2.0,0.5)$ \\
\hline Total & & $2.51\left(M_{w} 6.9\right)$ & $0-11$ & $40 \times 10$ & \\
\hline Reference & \multicolumn{5}{|c|}{$\mathrm{S}$ wave velocity $\left(V_{S}\right)=3.6 \mathrm{~km} / \mathrm{sec}$, Rupture velocity $\left(V_{R}\right)=3.0 \mathrm{~km} / \mathrm{sec}$} \\
\hline
\end{tabular}




\section{GENERAL CHARACTERISTICS OF PHGA ATTENUATION}

Figure 5 presents the relationship between the PHGA records for each subsurface ground condition and the closest distance $(D)$ from the Earth's surface projection of the fault rupture to the recording site. In this case, the projection is simplified to be a straight-line (fault line), as shown in previous figures, over a length of approximately $40 \mathrm{~km}$ based on the fault mechanism solution by Kikuchi (1995). The assumed positions of the fault line edges are $\left(34.52^{\circ} \mathrm{N}, 134.90^{\circ} \mathrm{E}\right)$ and $\left(34.73^{\circ} \mathrm{N}, 135.25^{\circ} \mathrm{E}\right)$, respectively. The solid and dashed lines in Fig. 5 denote the mean and mean \pm one standard deviation attenuation relationships for "rock" or "stiff soil" proposed by Joyner and Boore (1981) as follows.

$$
\log \mathrm{PHGA}=-1.02+0.249 M_{w}-\log r-0.00255 r
$$

where

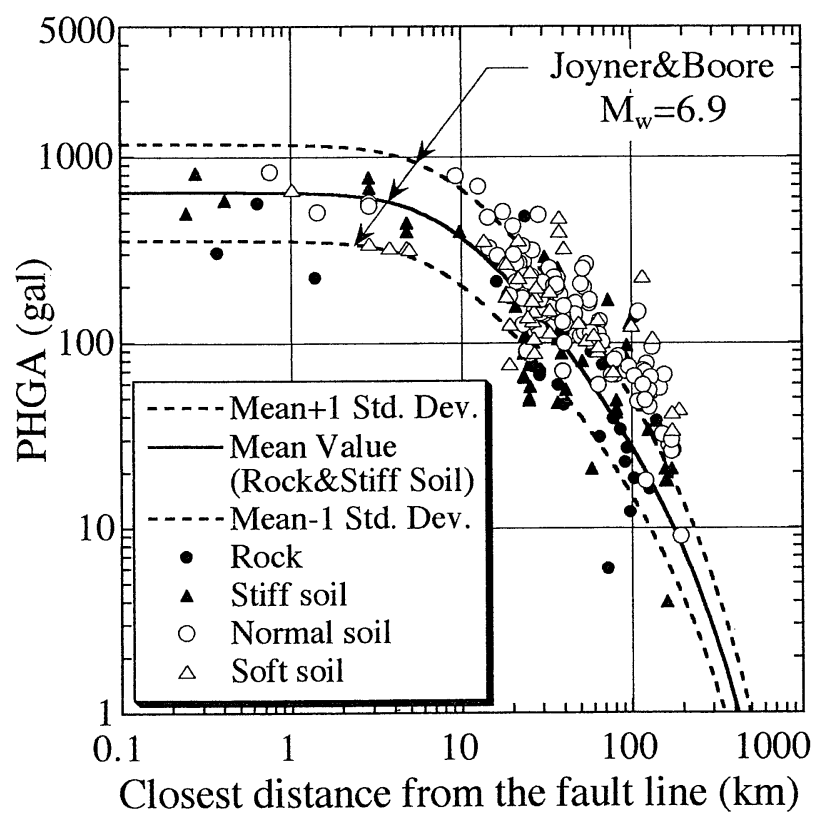

Fig. 5. PHGA attenuation for each subsurface condition

Table 2. Classification of subsurface conditions

\begin{tabular}{c|c|c}
\hline \multirow{2}{*}{$\begin{array}{c}\text { Classification } \\
\text { in this study }\end{array}$} & \multicolumn{2}{|c}{ Classification of design code for bridges } \\
\cline { 2 - 3 } Rock & Soil condition & \multicolumn{1}{c}{ Geological definition } \\
\hline \multirow{2}{*}{ Stiff } & Group 1 & $\begin{array}{l}\text { Tertiary or older rock, } \\
\text { or diluvium with } H<10 \mathrm{~m}\end{array}$ \\
\hline \multirow{2}{*}{ Normal } & Group 2 & $\begin{array}{l}\text { Diluvium with } H \geqq 10 \mathrm{~m}, \\
\text { or alluvium with } H<10 \mathrm{~m}\end{array}$ \\
\cline { 3 - 3 } & $\begin{array}{l}\text { Alluvium with } H<25 \mathrm{~m} \\
\text { including soft layer with } \\
\text { thickness less than } 5 \mathrm{~m}\end{array}$ \\
\hline Soft & Group 3 & $\begin{array}{l}\text { Other than the above, } \\
\text { usually soft alluvium } \\
\text { or reclaimed land }\end{array}$ \\
\hline
\end{tabular}

$$
r=\left(D^{2}+7.3^{2}\right)^{1 / 2}
$$

PHGA: peak horizontal ground acceleration (g)

$M_{w}$ : moment magnitude

$D: \quad$ closest distance $(\mathrm{km})$

The recording sites are divided into four categories such as "rock", "stiff soil", "normal soil" and "soft soil". This follows the classification proposed by Design Code for Bridges in Japan (1990), as shown in Table 2. In addition, Group 2 in the Design Code has been subdivided into two categories such as "stiff soil" and "normal soil". It can be seen that most of the PHGAs recorded at distances shorter than $10 \mathrm{~km}$ fall within the \pm 1 standard deviation bands and through all distances, the PHGA records on "rock" and "stiff soil" conform well with the mean attenuation relationship for "rock" or "stiff soil", by Joyner and Boore. Consequently, it was recognized that PHGAs observed near the fault rupture zone, which were induced by the Hyogoken-Nambu earthquake of $M_{w}=6.9$, were never considerably greater than the $\mathrm{PH}-$ GAs associated with earthquakes in the western U.S.A.. In addition, this figure shows that the PHGAs recorded at distances from $10 \mathrm{~km}$ up to $200 \mathrm{~km}$ on "normal soil", and "soft soil" sites greatly exceed the mean attenuation relationship for "rock" or "stiff soil". It is obvious that this reflects the site-specific amplification induced by deep and soft soils.

At distances shorter than $10 \mathrm{~km}$, however, most of the PHGAs records on "normal soil" and "soft soil" were lower than the mean value. This is because the strong nonlinear effect (i.e. softening and liquefaction) induced by deep and soft soils corresponding to "normal soil" and "soft soil" reduces the PHGAs on ground surface under very high level bedrock shaking. Figure 6 shows the strong ground motions typical of this case, which were observed at the Port Island vertical array on reclaimed land operated by Kobe city during this event. Seed et al. (1990) pointed out that "less"' amplification due to the nonlinear effect of the subsurface soils would occur when the PHGAs on bedrock outcroppings would exceed approximately 400 gal. For this event, the PHGAs on "rock" and "stiff soil" would be over $400 \mathrm{gal}$ in the fault rupture zone.

\section{DIRECTIVITY EFFECT ON PGA ATTENUATION}

In the first section, it was pointed out that the regional distribution of magnitudes of PHGAs during this event might be strongly biased by the source mechanism. This regional bias was therefore evaluated quantatively through the attenuation relationships based on the PGA records.

The dataset used in this analysis consists of $240 \mathrm{PH}-$ GAs and 192 PVGAs (peak vertical ground acceleration values), which were originally published by each organization. The larger value of the two horizontal components or composed value of them for PHGA was used. Recording sites are classified according to the subsurface ground conditions into two categories, "STIFF 


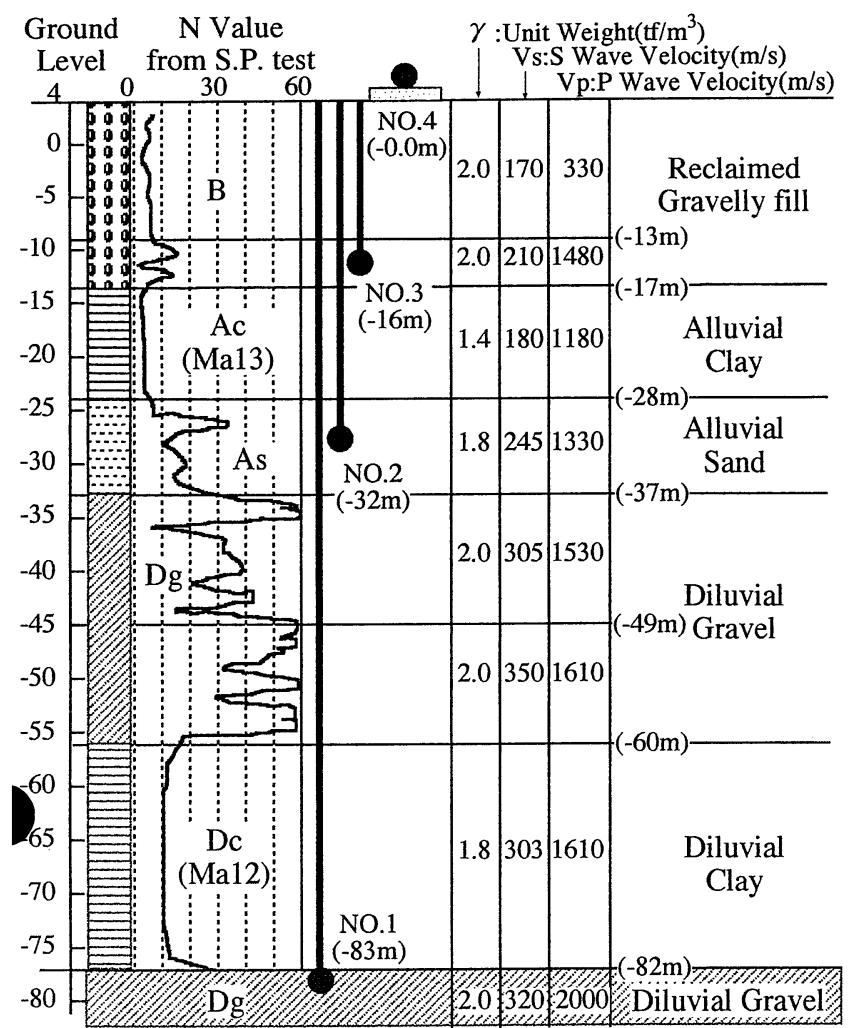

(a) Instrumentation and boring logs

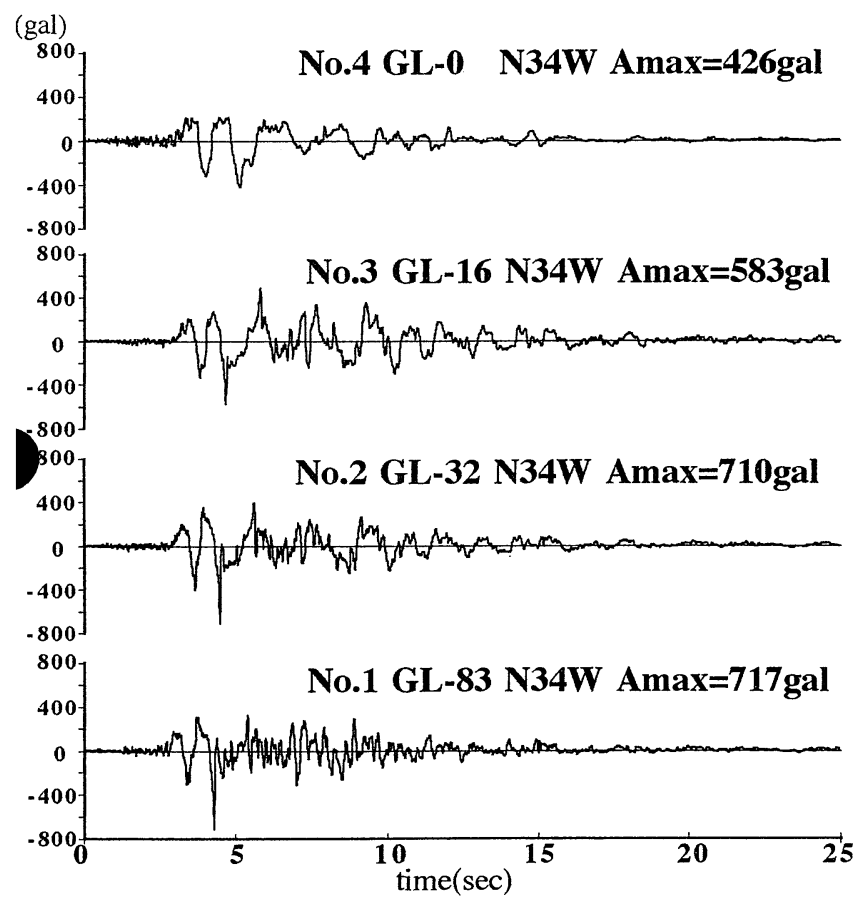

(b) Accelerograms converted to the major axis

Fig. 6. Strong ground motions on Port Island

GROUND" and "SOFT GROUND". Recording sites described by "rock" or "stiff soil" in previous classification are assigned to the category of "STIFF GROUND" and the others to "SOFT GROUND". In addition, the PGA records are divided into two datasets according to the site location relative to the fault line based on the boundary lines as shown in Fig. 1 or Fig. 7. One dataset consists of the PGA records in area A with an inner angle of $90^{\circ}$ for which the central direction is parallel to the fault strike and the other consists of those in area B for which central direction is perpendicular to the fault strike.

The PGA records belonging to each of the classified datasets were fitted by linear regression using the same attenuation formula as follows.

$$
\log \mathrm{PGA}=-\log X_{\text {eq }}-b \cdot X_{\text {eq }}+c
$$

This attenuation formula was derived from the farfield approximation for S waves (Joyner and Boore 1981, Takemura 1993) which are radiated from a point source in a homogeneous, isotropic, unbounded medium. The first term in the right-hand side of Eq. (2) represents geometric spreading and the second one represents anelastic attenuation.

$X_{\text {eq }}$ in Eq. (2) is a measure of distance, so-called "equivalent hypocentral distance (EHD)", proposed by Takemura (1993). $X_{\mathrm{eq}}$ makes it possible to evaluate PGA attenuation through all distances by using a far-field formula like Eq. (2) more reasonably than other alternatives such as the closest distance, hypocentral distance or epicentral distance, because it essentially includes the effects of fault size, fault geometry, inhomogeneous slip on the fault and site location on PGA attenuation. Figure 7 shows the schematic diagram of $X_{\text {eq }}$ calculation for the $40 \times 15 \mathrm{~km}$ size fault modeling this event. The following equation was used to calculate $X_{\text {eq }}$ assuming homogeneous slip on the fault.

$$
\frac{1}{X_{\text {eq }}^{2}}=\frac{\sum_{i=1}^{N} \sum_{j=1}^{M} \frac{1}{X_{i j}^{2}}}{N \times M}
$$

$X_{i j}$ represents the distances from each recording site to the center of each $40 \times 15$ small square segments.

The coefficent value " $b$ " related to anelastic attenuation was determined based on the PGA records on "STIFF GROUND" in area B and applied to all the other classified datasets, because the PGA dataset in area

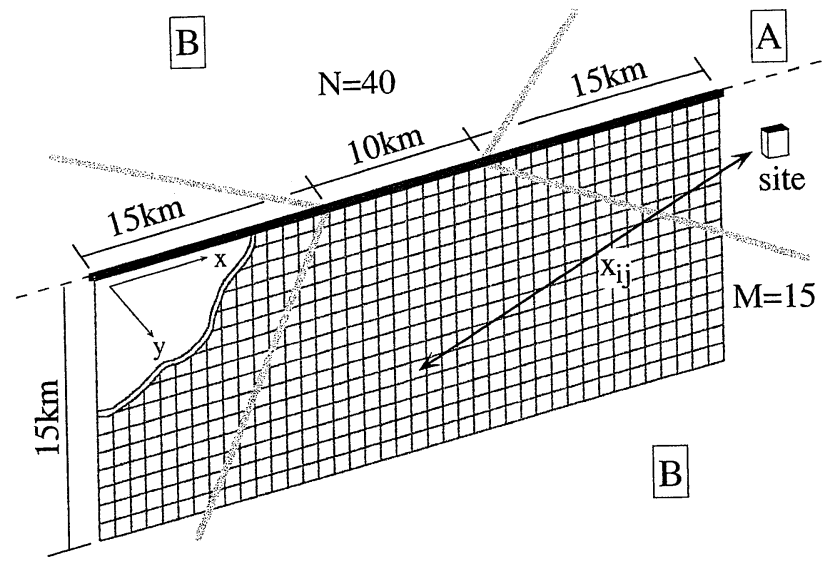

Fig. 7. Schematic diagram of $X_{\text {eq }}$ calculation 
Table 3. Results of the regression analysis

\begin{tabular}{|c|c|c|c|c|c|}
\hline Area & Ground & Component & $\begin{array}{c}\text { Coefficient } \\
b\end{array}$ & $\begin{array}{c}\text { Coefficient } \\
c\end{array}$ & $\underset{S}{\text { Std. Dev. }}$ \\
\hline \multirow{4}{*}{ A } & \multirow{2}{*}{ Stiff } & PHGA & 0.0021244 & 3.8340 & 0.18637 \\
\hline & & PVGA & 0.0050384 & 3.7588 & 0.24821 \\
\hline & \multirow{2}{*}{ Soft } & PHGA & 0.0021244 & 4.0408 & 0.20988 \\
\hline & & PVGA & 0.0050384 & 3.9473 & 0.23238 \\
\hline \multirow{4}{*}{ B } & \multirow{2}{*}{ Stiff } & PHGA & ${ }^{*} 0.0021244$ & 3.6834 & 0.20030 \\
\hline & & PVGA & ${ }^{*} 0.0050384$ & 3.5556 & 0.19311 \\
\hline & \multirow{2}{*}{ Soft } & PHGA & 0.0021244 & 3.8833 & 0.14979 \\
\hline & & PVGA & 0.0050384 & 3.7785 & 0.24268 \\
\hline
\end{tabular}

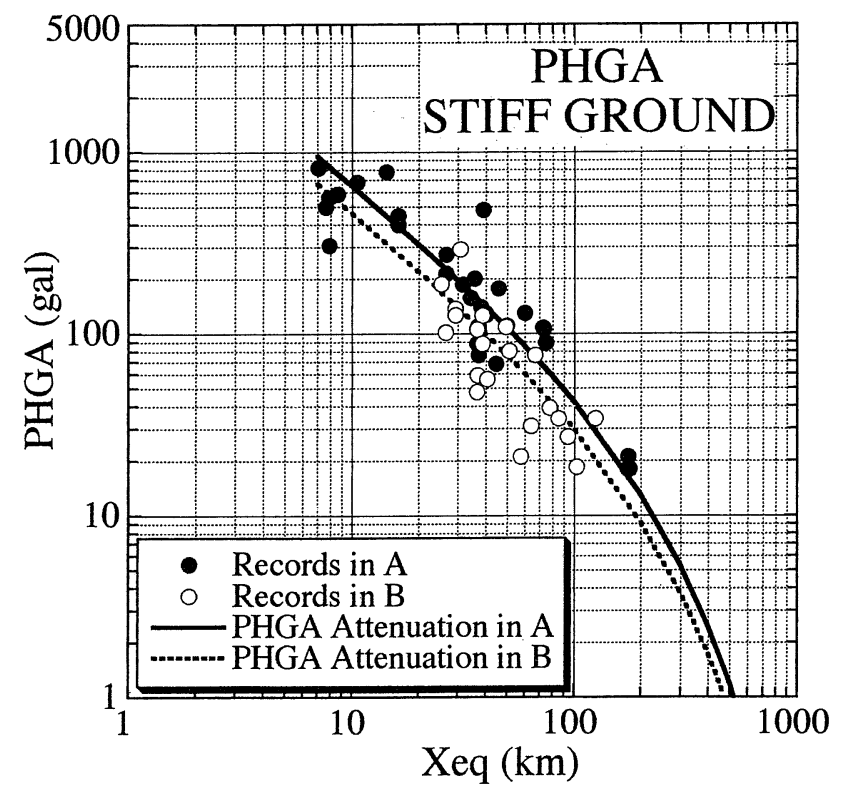

(a) STIFF GROUND

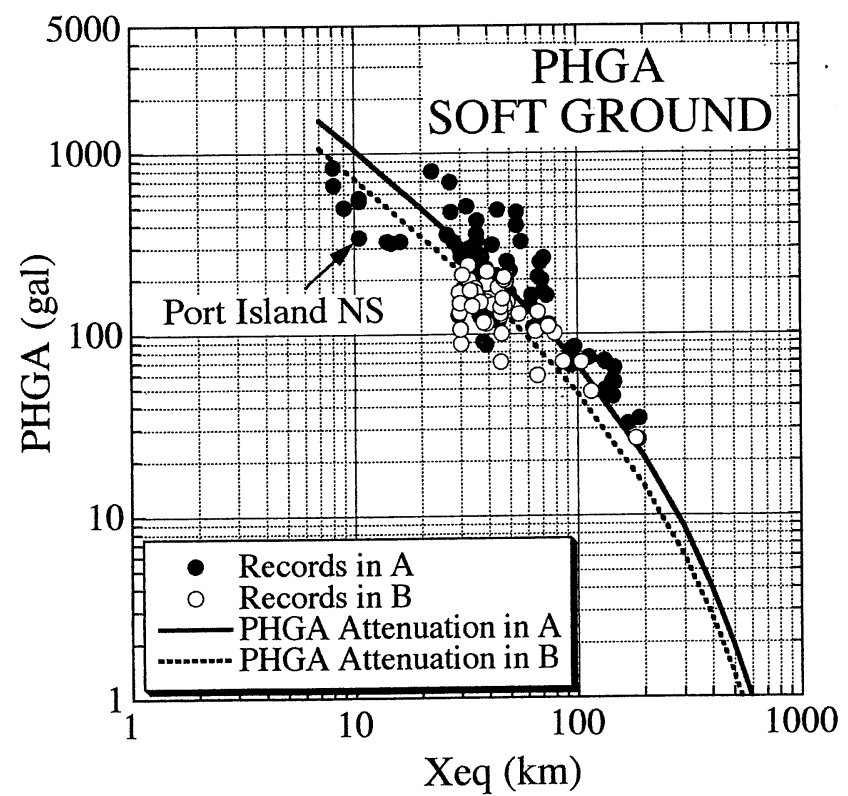

(b) SOFT GROUND

Fig. 8. PHGA attenuation versus $X_{\text {eq }}$ : (a) Stiff ground; (b) Soft ground
B seems to be less biased than in area A by either geologic site conditions or the error caused by inadequate sampling on distances. Consequently, the coefficent " $c$ " incorporates all the effects, such as directivity, radiation pattern, local site amplification depending on subsurface ground conditions, magnitude dependence and others, except for distances.

The coefficent values obtained from the regression analysis are listed in Table 3 . The parameter " $s$ " is the standard deviation on log PGA calculated from the regression analysis. All the values of " $s$ " for PHGA are smaller than that of 0.26 given by Joyner and Boore (1981). It is of interest to note that the coefficent value " $b$ ", for PHGA is very similar to that of 0.00255 in Eq. (1) given by Joyner and Boore.

This means that anelastic attenuations are approximately comparable between the Hanshin area affected by this event and the western U.S.A. The PVGAs seem to attenuate more rapidly than the PHGAs, since the coefficent value " $b$ " for PVGA is about twice that for PHGA.

In Fig. 8 and Fig. 9, PGA attenuations versus $X_{\text {eq }}$ for each of the classified datasets are shown. In these figures, the attenuation curves at distances shorter than about 7 $\mathrm{km}$ are not lined, for $X_{\mathrm{eq}} \approx 7 \mathrm{~km}$ means that the recording site is located just on the fault line.

Figure 8(a) shows a plot of PHGA attenuation on "STIFF GROUND" versus $X_{\text {eq }}$. The shaking levels on the fault line are from 700 to 900 gal. It can be seen that the PHGAs in area A exceed those in area B by about 50 percent on an average.

This tendency is common to all PGA attenuations shown here. It must be concluded therefore that this regional difference in PGA attenuation between in area $\mathrm{A}$ and area $B$ during this event was caused mainly by the directivity effect, since the effects of fault geometry, fault size and site location are excluded by introducing $X_{\text {eq }}$ and the local site effects are reduced by site classification according to subsurface ground conditions. In addition, the effect of the radiation pattern on PGA in area $A$ is much the same as in area $B$ considering the fault mechanism for this event. Based on the energy summation method, Koyama (1987) pointed out that the peak values of short period waves in area $\mathrm{A}$ affected by the directivity were greater than those in area B by about 70 percent maximum. Our results are nearly equivalent to this value.

PHGA attenuation on "SOFT GROUND" shown in Fig. 8(b) is greater than that on "STIFF GROUND"' by about 50 percent on an average due to the local site effects. In addition, in this figure, some less amplified records were observed at distances shorter than $20 \mathrm{~km}$ due to strong nonlinearlity of the subsurface soils.

In addition, it can be stated that the PVGAs on "SOFT GROUND" have higher amplitudes than those on "STIFF GROUND" due to the local site effects as shown in Fig. 9.

PVGA attenuation on "STIFF GROUND" shown in Fig. 9(a) is smaller than PHGA attenuation on "STIFF GROUND" by about 30 percent on an average and the shaking levels on the fault line are from 500 to 700 gal. 


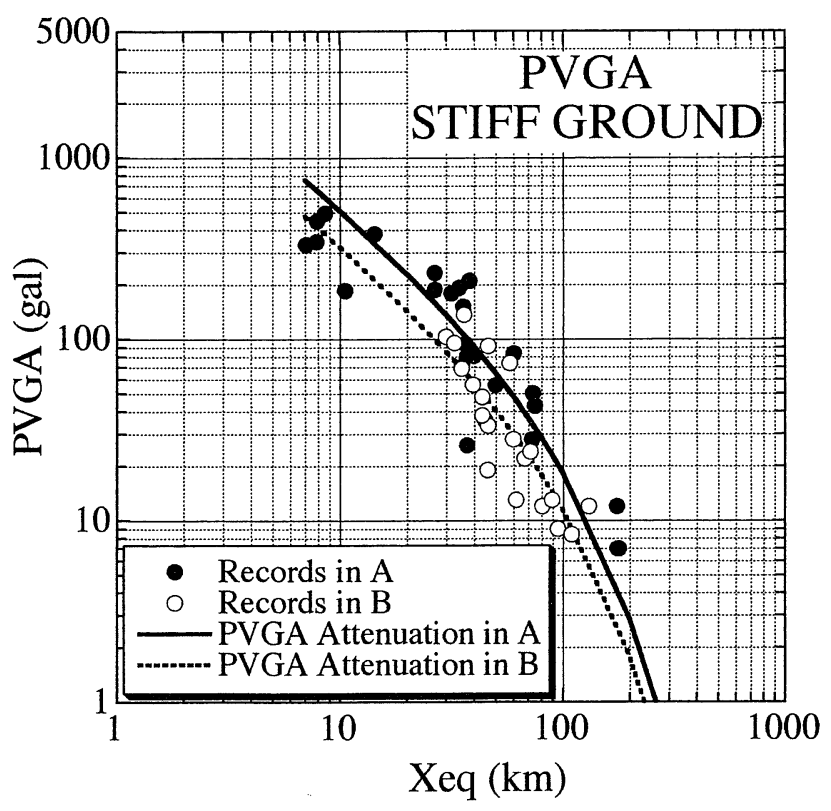

(a) STIFF GROUND

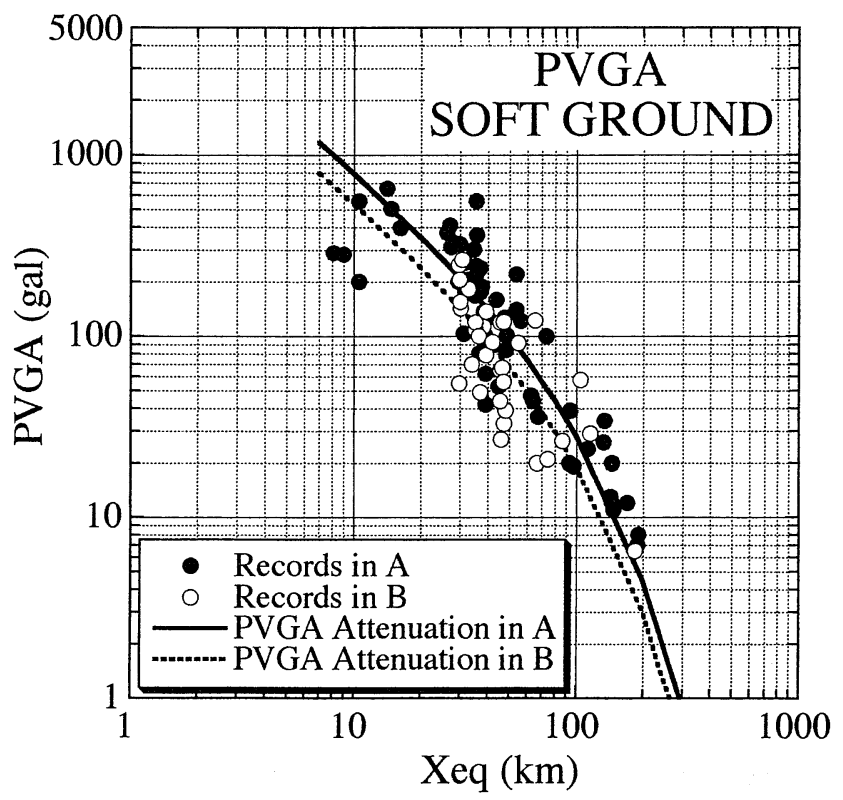

(b) SOFT GROUND

Fig. 9. PVGA attenuation versus $X_{\text {eq }}$ : (a) Stiff ground; (b) Soft ground

From this relationship between PHGA and PVGA revealed by the regression analysis, it was found that this event had not generated extraordinary high PVGAs.

Figure 10 shows a plot of PHGA attenuation on "STIFF GROUND" versus the closest distance instead of $X_{\text {eq }}$. Two attenuation curves "upper" and "lower" are drawn for each area based on the relationship varying with azimuth angles between $X_{\text {eq }}$ and the closest distance. This figure based on the closest distance shows that at distances longer than $20 \mathrm{~km}$, there are no difference in PHGA attenuation between the two areas but as distances are shorter, the PHGAs in area A are higher than those in area B. Near the fault line, PHGA attenuation

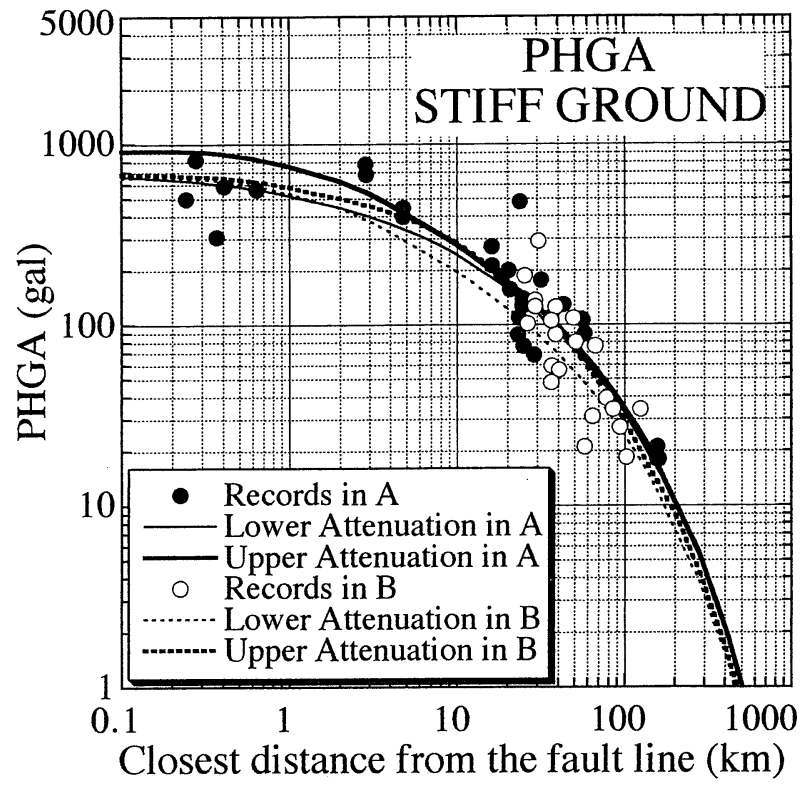

Fig. 10. PHGA attenuation versus the closest distance

conforms well with the PHGA records and an upper limitation with the values of approximately from 700 to 900 gal is noted.

Figure 11 shows a comparison of PHGA attenuations on 'SOFT GROUND" between north-west area B' and south-east area B", separating B area by the fault line. From this figure, it is found that there are no obvious differences in PHGA attenuations between area $\mathbf{B}^{\prime}$ and area $\mathrm{B}^{\prime \prime}$.

Figure 12 presents the PHGA/PVGA ratio attenuation versus $X_{\text {eq }}$ for each of the subsuface ground conditions. PHGA/PVGA ratio on "SOFT GROUND" shows a small value near the fault rupture zone especially and rapidly increases at distances longer than $30 \mathrm{~km}$.

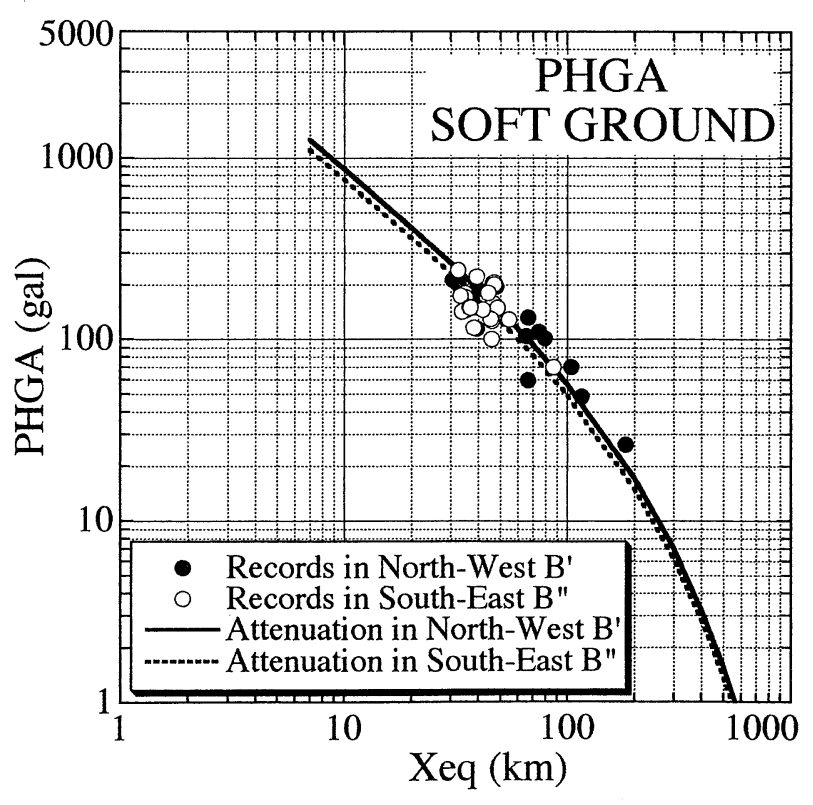

Fig. 11. Comparison of PHGA between $B^{\prime}$ and $B^{\prime \prime}$ 


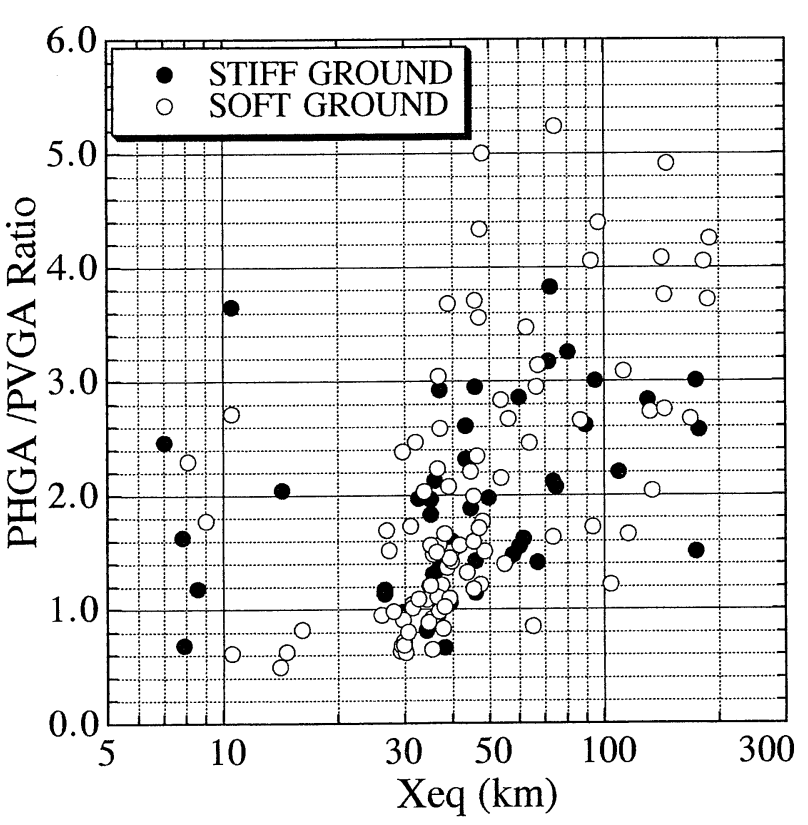

Fig. 12. PHGA/PVGA attenuation versus $X_{\text {eq }}$

This tendency is not clear for "STIFF GROUND". From this, it can be seen that the small amplified PHGAs make relatively higher PVGAs to be conspicuous on "SOFT GROUND" near the fault rupture zone. This feature depends on actual "softening and liquefaction" of the subsurface soils.

\section{CONCLUSIONS}

The main conclusions from this study are summarized as follows;

1) For the Hyogoken-Nambu earthquake, theoretical $S$ wave radiation from strike slip fault can explain the characterized regional distribution of the PHGAs and major principal axes orientation perpendicular to the fault strike.

2) The PGAs in area $A$ (the strike direction area) are greater than those in area $\mathrm{B}$ by about 50 percent on an average. This results from the directivity effect.

3) The unusually small PHGA/PVGA ratios near the fault rupture zone result from the strong nonlinearlity of the subsurface soils.

4) There are no obvious differences in PHGA attenuations between north-west area $\mathrm{B}^{\prime}$ and south-east area $\mathrm{B}^{\prime \prime}$. 5) The PHGA attenuations during this event are nearly equivalent to those associated with events which have occured in the western U.S.A.

A preference for PGA as the parameter for describing the strong ground motion characteristics is not implied. However, its widespread use is recognized. Longer period motion characteristics must be investigated based on their relationship to structural damage. The character- istics of strong ground motion spectra must be examined.

\section{ACKNOWLEDGEMENTS}

The authors would like to express their deep appreciation to all the staff of various organizations for providing valuable strong ground motion records from the 1995 Hyogoken-Nambu earthquake quickly.

\section{REFERENCES}

1) CEORKA (1995): No. 5 Meeting documents (in Japanese).

2) Ejiri, J., Goto, Y. and Toki, K. (1995): "Strong ground motion characteristics during the 1995 Hyogoken-Nambu earthquake," JSCE Earthquake Engineering Symposium, PP. 237-240 (in Japanese).

3) Igarashi, S., Moriguchi, H., Hisakawa, E., Suzuki, T. and Hakuno, M. (1995): "Relationship between vertical ground motion induced by topographic effects and structural damage," JSCE Earthquake Engineering Symposium, PP. 77-80 (in Japanese).

4) Japan Road Association (1990): “Design code for bridges-earthquake resistant design-,' Vol. V (in Japanese).

5) JGS (1992): Kansai Jiban (in Japanese).

6) Joyner, W. B. and Boore, D. M. (1981): “Peak horizontal acceleration and velocity from strong motion records from the 1979 Imperial Valley-California-earthquake," BSSA, Vol. 71, No. 6, PP. 2011-2038.

7) JSCE (1995): Preliminary Report on the 1995 South Hyogo Prefecture Earthquake (in Japanese).

8) Kamae, K., Irikura, K. and Fukuchi, Y. (1991): “Prediction of strong ground motion based on scaling law of earthquake by stochastic synthesis method," Journal of S.C.E, AIJ, No. 430, PP. 1-9 (in Japanese).

9) Kaneda, Y., Omote, Y., Kuwabara, T., Namiki, K. and Hirama, K. (1995): "Preliminary report on the 1995 South Hyogo Prefecture earthquake-on the viewpoint of geology and seismology-," Report of Obayashi Corporation Technical Research Institute (in Japanese).

10) Kikuchi, M. (1995): "Source mechanism of Hyogoken-Nambu earthquake," January 17, 1995, GSJ Preliminary Report on the 1995 South Hyogo Prefecture Earthquake, PP. 117-122 (in Japanese).

11) Koyama, J. (1987): “Short period seismic directivity,' Zishin, Vol. 40, PP. 397-404 (in Japanese).

12) Nakamura, Y., Hidaka, K., Saita, J. and Sato, S. (1995): "Strong accelerations and damage of the 1995 Hyogo-Ken-Nambu earthquake,"' JR Earthquake Information No. 23b.

13) Ohno, S., Ohta, T., Ikeura, M. and Takemura, M. (1993): "Revision of attenuation formula considering the effect of fault size to evaluate strong motion spectra in near field,"' Tectonophisics, 218, PP. 69-81.

14) Seed, R. B., Dickenson, S. E. and Idriss, I. M. (1990): “Geotechnical factors controlling damage patterns in the Loma Prieta earthquake of October 17, 1989,', Special session of JGS No. 25 annual conference, PP. 1-39.

15) Takenaka Corporation (1995): NO. 2 Report of great Hanshin disaster (the 1995 South Hyogo Prefecture earthquake) (in Japanese).

16) The National Research Institute for Earth Science and Disaster Prevention, Science and Technology Agency (1995): Prompt report on strong-motion accelerograms No. 46-January 17, 1995 Southern Hyogo Prefecture-(in Japanese).

17) Toki, K., Goto, Y., Ejiri, J. and Sawada, S. (1995): “A brief review of source effects and local site Effects during Hyogo-ken Nambu earthquake,"' Journal of JSCE (in Japanese). 